\title{
MATHEMATICAL MODELING OF SIZE FEATURES
}

\author{
Krasimir Krastev \\ Trakia University, Faculty of Technics and Technologies \\ Graf Ignatiev 38, 8600 Yambol, Bulgaria, e-mail: krasikrystev@gmail.com
}

\begin{abstract}
Because of the high variability of size features and their random nature made observations on fifty four pregnant women from the second to the ninth months of the pregnancy.

The main objective of the article is to determine the changes in the diagnostic parameter "waist" in the pregnancy and to do a mathematical model based on the regression analysis.
\end{abstract}

Keywords: methods of regression analysis, size features.

\section{INTRODUCTION}

Motherhood is desirable and exciting event for every woman. This physiological state does not exclude her from participation in work and social activities. The mother wishes to retain their place in society, has right to remain stylish and attractive throughout the pregnancy. Therefore she needs not only domestic and everyday clothes but working and official wear also. The types of clothing for pregnant women should be considered in connection with their seasonal use - winter, summer and transient. The pregnant women need more than 20 kinds of products (only accessories are not required to be specific). In the eighties of 20 century the manufacturers have taken up the difficult task - making these types and offering them in specialized stores and stands. Clothing for pregnant women became an assortment of the fashion houses and went on the podium in the collections of fashion shows.

Much of expectant mothers prefer to buy confection in shops to custom made wear but at this point marketing network is not able to offer sufficient choice or there are not some special types of clothing for this time of woman life [5].

The specifics of the confection for expectant mothers off equating it to a giant group where the volume of products increased total and changes in pregnancy are partial and specific.

For example, tights giant reach middle of the abdomen and tighten making them unsuitable. This concern the underwear and outerwear of the same group. For this reason, expectant mothers should be directed to the special assortments for pregnant women.

The good fit of clothing is the main quality of the garment which greatly concerns both consumers and people working in the fashion industry. They determine comfort, silhouette attractiveness in parallel with the design and the fabric.

During the pregnancy it is necessary to use more specific clothing adapted to the changing shapes of the body - more functional and practical. Condition of the pregnant suggests a tendency to varicose veins, edema, hypersensitivity and allergy which requires more careful selection of clothing in fabrics, cuts and accessories, as well as appropriate shoes.

\section{EXHIBITION}

Because of the high variability of feature signs and their random nature, depending on the particular case, there are no comprehensive research in this area and their mathematical processing $[1,2,3,4,6]$. The most important changes in a woman body during pregnancy that have occurred are weight, waist, and bust increasing. They are in direct relation with the size features required for constructing and modeling clothing.

IRTIIE Vol. 2, No. 2, 2014 ISSN 1314-8788 (print), ISSN 1314-8796 (online), doi: 10.15547/artte.2014.02.001 
Table 1. Distribution of waist size - month

\begin{tabular}{|c|c|c|c|c|c|c|c|c|}
\hline $\mathbf{N} \backslash$ month & 2 & 3 & 4 & 5 & 6 & 7 & 8 & 9 \\
\hline 1 & 63 & 63 & 65 & 72 & 76 & 83 & 87 & 93 \\
\hline 2 & 72 & 74 & 78 & 85 & 87 & 91 & 93 & 95 \\
\hline 3 & 73 & 74 & 79 & 84 & 87 & 92 & 94 & 97 \\
\hline 4 & 68 & 68 & 70 & 73 & 75 & 78 & 86 & 88 \\
\hline 5 & 63 & 63 & 69 & 73 & 79 & 80 & 81 & 88 \\
\hline 6 & 74 & 76 & 78 & 80 & 86 & 88 & 102 & 103 \\
\hline 7 & 78 & 78 & 82 & 88 & 92 & 99 & 103 & 104 \\
\hline 8 & 70 & 72 & 85 & 86 & 87 & 89 & 97 & 98 \\
\hline 9 & 69 & 72 & 87 & 91 & 93 & 93 & 100 & 103 \\
\hline 10 & 57 & 60 & 62 & 67 & 70 & 78 & 85 & 90 \\
\hline 11 & 86 & 87 & 92 & 93 & 94 & 96 & 99 & 99 \\
\hline 12 & 66 & 72 & 76 & 80 & 86 & 90 & 95 & 100 \\
\hline 13 & 64 & 68 & 70 & 74 & 78 & 86 & 93 & 100 \\
\hline 14 & 64 & 68 & 72 & 76 & 85 & 88 & 91 & 95 \\
\hline 15 & 80 & 81 & 83 & 88 & 94 & 96 & 98 & 100 \\
\hline 16 & 77 & 80 & 83 & 85 & 87 & 98 & 101 & 98 \\
\hline 17 & 72 & 73 & 82 & 84 & 88 & 90 & 93 & 94 \\
\hline 18 & 94 & 96 & 100 & 100 & 101 & 101 & 102 & 103 \\
\hline 19 & 62 & 70 & 72 & 76 & 79 & 81 & 86 & 98 \\
\hline 20 & 76 & 80 & 83 & 85 & 87 & 93 & 100 & 105 \\
\hline 21 & 78 & 80 & 83 & 85 & 86 & 87 & 90 & 90 \\
\hline 22 & 88 & 90 & 94 & 94 & 96 & 103 & 104 & 109 \\
\hline 23 & 83 & 84 & 90 & 95 & 100 & 100 & 101 & 102 \\
\hline 24 & 60 & 60 & 62 & 87 & 90 & 94 & 95 & 96 \\
\hline 25 & 90 & 94 & 98 & 99 & 100 & 101 & 103 & 105 \\
\hline 26 & 92 & 93 & 98 & 98 & 99 & 101 & 105 & 107 \\
\hline 27 & 89 & 90 & 91 & 99 & 102 & 105 & 106 & 111 \\
\hline 28 & 79 & 80 & 84 & 89 & 86 & 86 & 88 & 92 \\
\hline 29 & 87 & 87 & 90 & 90 & 94 & 99 & 100 & 103 \\
\hline 30 & 71 & 72 & 77 & 77 & 82 & 86 & 103 & 100 \\
\hline 31 & 86 & 87 & 87 & 87 & 92 & 94 & 99 & 106 \\
\hline 32 & 80 & 81 & 82 & 83 & 89 & 94 & 96 & 101 \\
\hline 33 & 78 & 79 & 80 & 84 & 84 & 89 & 95 & 96 \\
\hline 34 & 68 & 69 & 76 & 75 & 77 & 80 & 79 & 84 \\
\hline 35 & 92 & 93 & 94 & 94 & 97 & 104 & 103 & 108 \\
\hline 36 & 114 & 115 & 119 & 118 & 120 & 125 & 124 & 126 \\
\hline 37 & 90 & 91 & 93 & 93 & 95 & 93 & 98 & 101 \\
\hline 38 & 94 & 95 & 97 & 97 & 101 & 106 & 107 & 109 \\
\hline 39 & 84 & 85 & 87 & 88 & 90 & 90 & 91 & 93 \\
\hline 40 & 110 & 111 & 112 & 113 & 114 & 115 & 119 & 119 \\
\hline 41 & 94 & 95 & 96 & 97 & 98 & 102 & 107 & 110 \\
\hline 42 & 81 & 82 & 88 & 87 & 88 & 92 & 95 & 99 \\
\hline 43 & 73 & 74 & 75 & 76 & 88 & 87 & 87 & 92 \\
\hline 44 & 75 & 76 & 76 & 77 & 78 & 82 & 85 & 88 \\
\hline 45 & 84 & 85 & 87 & 90 & 93 & 94 & 96 & 99 \\
\hline 46 & 81 & 82 & 89 & 93 & 93 & 95 & 98 & 101 \\
\hline
\end{tabular}

IRTIIE Vol. 2, No. 2, 2014 ISSN 1314-8788 (print), ISSN 1314-8796 (online), doi: 10.15547/artte.2014.02.001 


\section{ARTIIE}

Ipplied Researreches in Technics, Technologies and Bductition Journal of the Faculty of Technics and Technologies, Trakia University https://sites.google.com/a/trakia-uni.bg/artte/

\begin{tabular}{|r|r|r|r|r|r|r|r|r|}
\hline 47 & 87 & 88 & 88 & 93 & 100 & 101 & 106 & 108 \\
\hline 48 & 91 & 92 & 94 & 96 & 100 & 104 & 107 & 111 \\
\hline 49 & 87 & 88 & 90 & 94 & 99 & 102 & 105 & 104 \\
\hline 50 & 95 & 95 & 96 & 95 & 95 & 99 & 100 & 103 \\
\hline 51 & 74 & 75 & 75 & 79 & 81 & 85 & 88 & 94 \\
\hline 52 & 79 & 80 & 77 & 75 & 86 & 88 & 89 & 94 \\
\hline 53 & 82 & 83 & 85 & 87 & 88 & 91 & 94 & 99 \\
\hline 54 & 93 & 94 & 93 & 97 & 96 & 98 & 99 & 102 \\
\hline $\begin{array}{l}\text { average } \\
\text { value }\end{array}$ & 79.94444 & 81.48148 & 84.64815 & 87.42593 & 90.51852 & 93.74074 & 97.18519 & 100.2407 \\
\hline $\begin{array}{l}\text { average } \\
\text { deviation }\end{array}$ & 11.93444 & 11.54113 & 11.23028 & 10.00491 & 9.31167 & 9.074503 & 8.543063 & 7.791953 \\
\hline
\end{tabular}

In this paper we confine to the preparation of a mathematical model using the method of regression analysis of size feature - waist size. The observations have done on fifty-four pregnant women from the second to the ninth month of pregnancy. The resulting data is displayed in Table 1.

The data obtained for each month can be displayed graphically in the following chart.

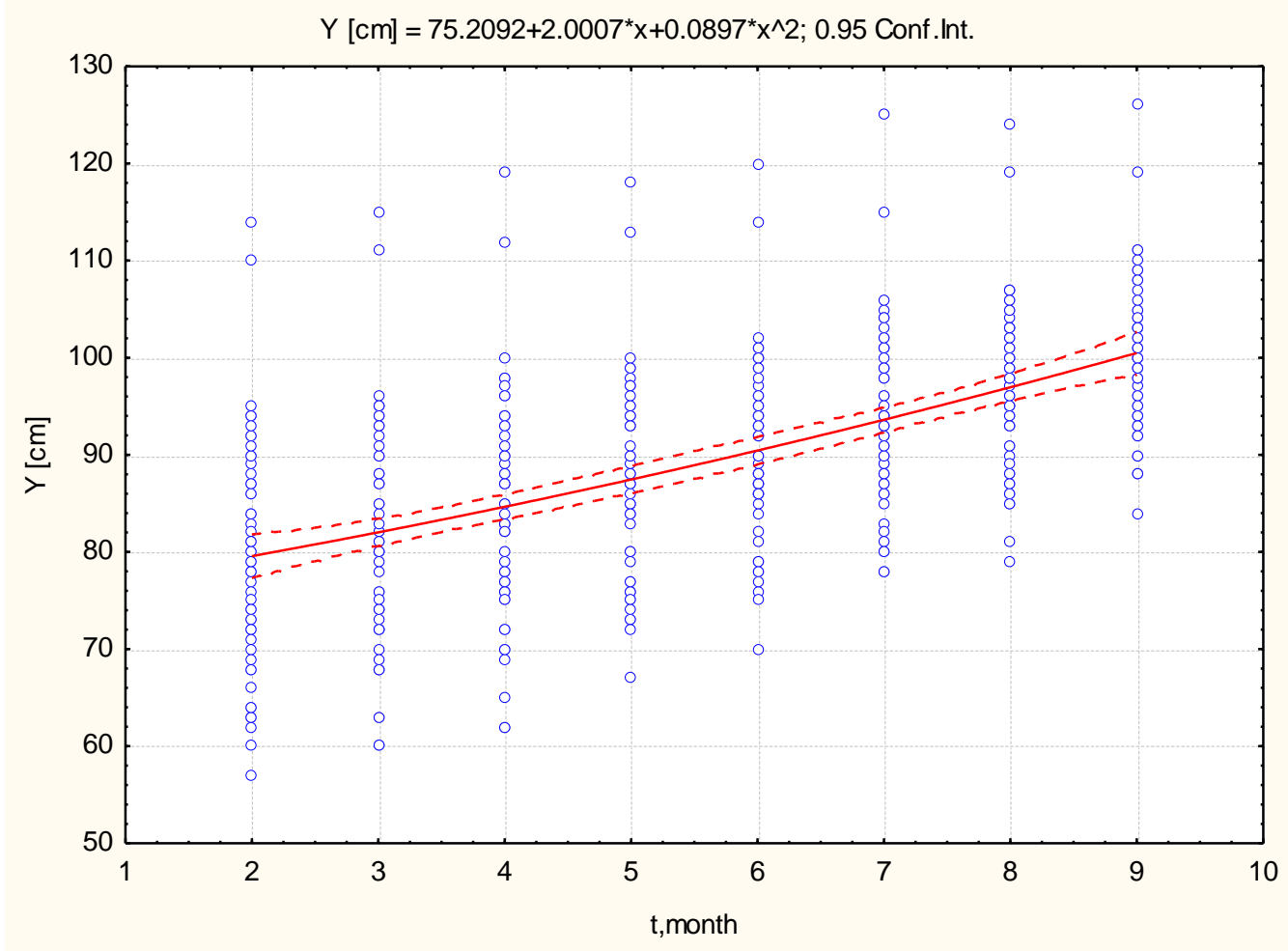

Figure 1. Chart of size feature of "waist size" in time

In order to avoid the accumulation we will show only a part of the individual implementations of size feature. Each obtained curve we can interpret as a random function with an uncaused argument - time.

IRTIIE Vol. 2, No. 2, 2014 ISSN 1314-8788 (print), ISSN 1314-8796 (online), doi: 10.15547/artte.2014.02.001 


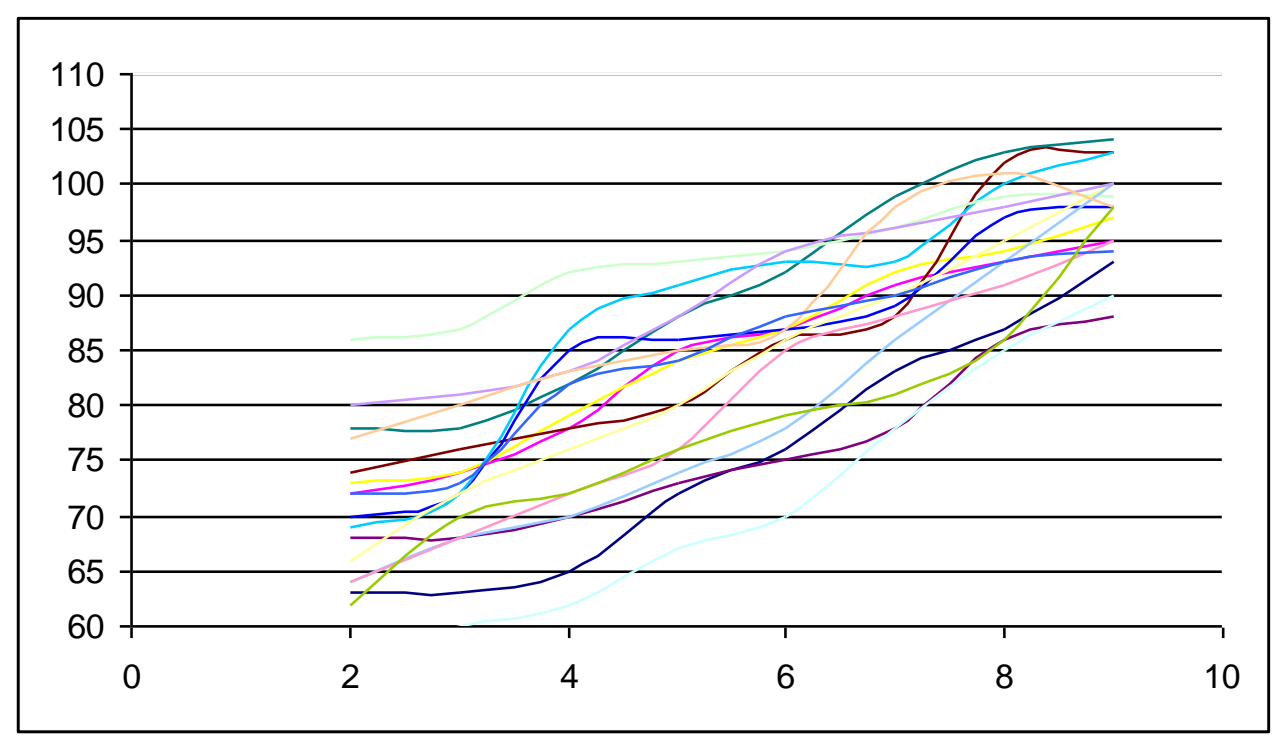

Figure 2. Chart of some of the various implementations of size feature

From the obtained chart we can conclude that the random process is relatively smooth and it has not got a chaotic nature. This can be calculated with correlation coefficients calculated for individual months showed in Table 2.

Table 2. Correlation coefficients calculated for individual months

\begin{tabular}{|c|c|c|c|c|c|c|c|c|}
\hline & 2 & 3 & 4 & 5 & 6 & 7 & 8 & 9 \\
\hline 2 & 1.000 & & & & & & & \\
\hline 3 & 0.992 & 1.000 & & & & & & \\
\hline 4 & 0.954 & 0.964 & 1.000 & & & & & \\
\hline 5 & 0.902 & 0.907 & 0.940 & 1.000 & & & & \\
\hline 6 & 0.888 & 0.892 & 0.909 & 0.962 & 1.000 & & & \\
\hline 7 & 0.866 & 0.871 & 0.876 & 0.932 & 0.962 & 1.000 & & \\
\hline 8 & 0.790 & 0.803 & 0.821 & 0.863 & 0.890 & 0.933 & 1.000 & \\
\hline 9 & 0.773 & 0.799 & 0.798 & 0.830 & 0.867 & 0.914 & 0.955 & 1.000 \\
\hline
\end{tabular}

By the obtained data we checked some mathematical models as suitable. The most suitable model is polynomial of second order that have the general form:

$$
y=b_{0}+b_{1} t+b_{2} t^{2}
$$

Statistical processing of the data shows that the coefficient of determination $R^{2}=0.998$, practical unit, shows that almost $100 \%$ of the change of the parameter $y$-waist size is due to controllable factors $t$ and it is described by the using model. From several studied models, in this model the determination coefficient is the highest. Statistically significant are all coefficients of the polynomial. They are as follows:

$$
b_{0}=75,21 ; b_{1}=2,00 ; b_{2}=0,08 \text {. }
$$

IRTIIE Vol. 2, No. 2, 2014 ISSN 1314-8788 (print), ISSN 1314-8796 (online), doi: 10.15547/artte.2014.02.001 


\section{IRTIL $\vee>$}

Ipplied Resseirlohes in Technics, Technologies and Eductation

Journal of the Faculty of Technics and Technologies, Trakia University https://sites.google.com/a/trakia-uni.bg/artte/

Fisher criterion $F=1669$ and its corresponding probability $p<0.0000$ indicates that the model describes the essential part of modification'of $y$.

The final form of the equation is:

$$
y=75,21+2,00 t+0,08 t^{2}
$$

Resulting regression model describes a surface $y=f(t)$ in $R^{2}$ that we can show graphically.

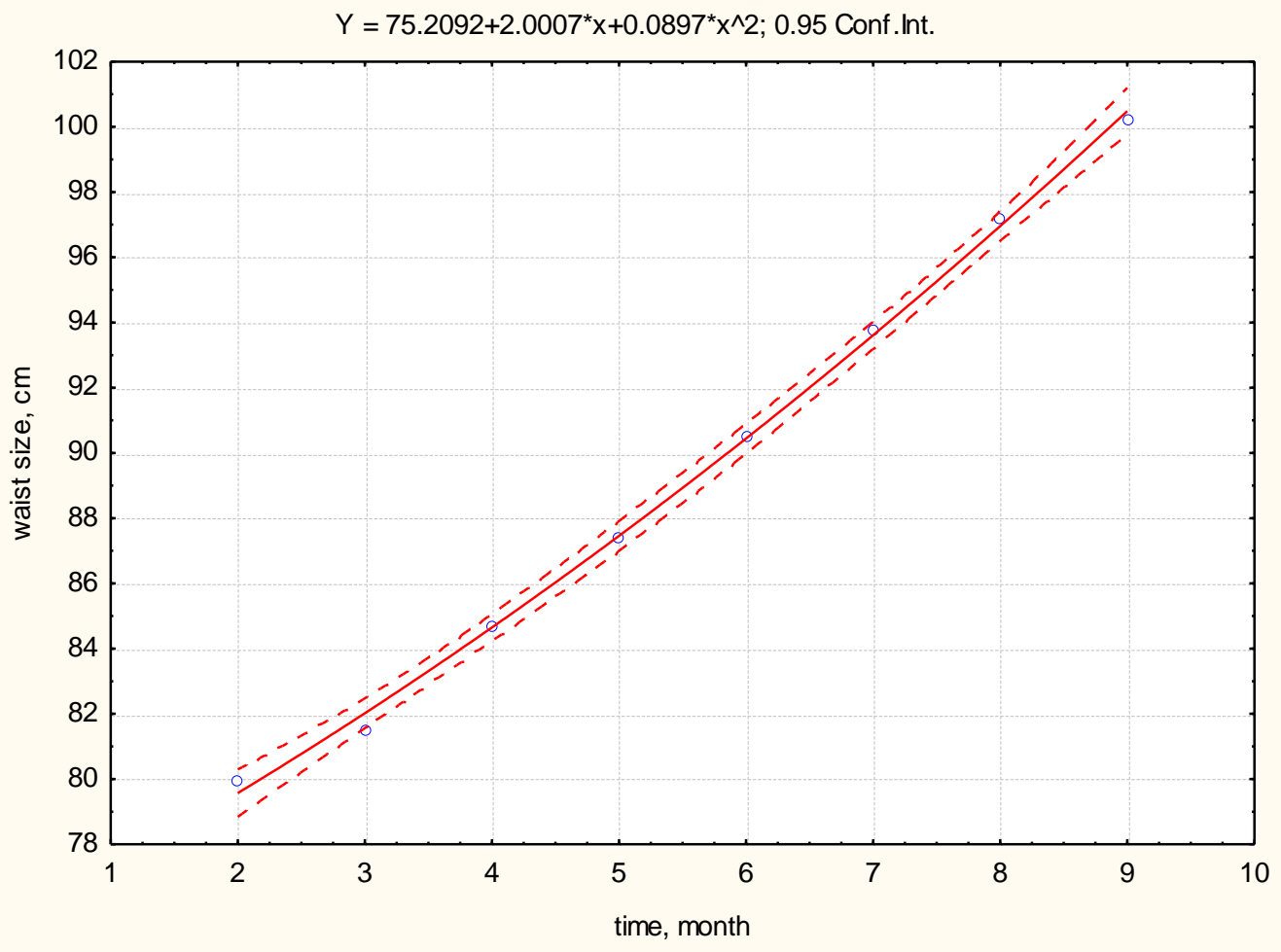

Figure 2 Regression line and area of the predicted value of $Y$

From obtained regression equation and the calculated statistics we can try to predict the change of size feature in each case (realization). This will eliminate the constant and will put it as an initial condition for each implementation:

$$
y=c+2,00 t+0,08 t^{2}, y\left(t_{0}\right)-2,00 t_{0}+0,08 t_{0}^{2}=c
$$

or

$$
y=y\left(t_{0}\right)-2,00 t_{0}+0,08 t_{0}^{2}+2,00 t+0,08 t^{2} \pm \sigma
$$

where $\sigma$ is calculated in Table 1 .

IRTIIE Vol. 2, No. 2, 2014 ISSN 1314-8788 (print), ISSN 1314-8796 (online), doi: 10.15547/artte.2014.02.001 


\section{IRTITE \\ Ipplied Researreches in Technics, Technologies and Bductition \\ Journal of the Faculty of Technics and Technologies, Trakia University https:///ites.google.com/a/trakia-uni.bg/artte/}

\section{CONCLUSIONS}

From the obtained results we can conclude:

1. We have obtained data of the type of process and calculated correlation coefficient.

2. We have obtained a mathematical model of size feature - "waist size" that in details describes that size.

3. We have obtained an analytic dependence that allows prediction of size feature in the different periods of pregnancy. This allows engineers and designers to provide adequate allowance for freedom when they design clothing for pregnant women.

\section{REFERENCES}

[1] Stanchev D., A. Asenov, N. Stancheva, V. Stoykova. (2004). Specified Empiric relation for the slippage characteristics. EE\&AE '2004 - International Scientific Conference. 0305.06.2004, Rousse, Bulgaria.

[2] Georgieva K., V. Stoykova. (2011). Develop a training program modules for general technical disciplines is the application of e-technologies. Trakia Journal Of Sciences, 2011 , No 4, pp. 5-8.

[3] Kazlacheva Z. (2010). The Use of Suitable Methods of Statistical Analysis in Fashion Design and Clothing Constructing. Piraeus, Greece, Proceedings of the International Scientific Conference eRA-5, 15-18 September 2010, pp. 432-437.

[4] Krastev K., R. Yorgova, S. Dineva. (2013). Acceptance of New Learning and Teaching Methods by Students., The $8^{\text {th }}$ International conference on virtual learning, Virtual learning - Virtual reality, 2013, pp. 102-107, ISSN 1844-8933.

[5] Zlatev Z, J. Ilieva. (2013). Possibilities of application of additional devices to the interactive presentation tools for analysis of fabrics, ICTTE 2013 International Conference on Technics, Technologies and Education, Faculty of Technics and Technologies, Trakia University, October 30-31 2013, pp. 209-216, ISSN 1314-9474.

[6] Zlatev Z., M. Mladenov. (2013). Evaluation of Pork Freshness by Computer Vision. Information, Communication and Control Systems and Technologies. Year II, No. 1, 2013, pp.37-42, ISSN-1314-7455. 